\title{
MASSIVE PULMONARY EMBOLISM DURING ANAESTHESIA: A REPORT OF TWO CASES
}

\author{
R. A. Browne, M.B., CH.B., F.F.A.R.C.S.(ENG.), \\ AND D. V. CaTtON, M.D., F.R.C.P.(C)
}

THE FIRST clear description of a case of pulmonary embolism was recorded by Hèlie in $1837 .{ }^{1}$ By the early twentieth century it was realized that pulmonary embolism was a common complication of surgical operations. ${ }^{2}$

The incidence of pulmonary embolism at the Hamilton General Hospital over the period January to December 1966 was 40 cases out of 14,568 admissions. Of these, 21 were fatal ( 13 medical and 8 surgical).

Patients with a fractured neck of femur run, as a group, a specially high risk of pulmonary embolism. ${ }^{3}$ They are usually old people and are fairly immobile postoperatively in spite of operative fixation of the fracture. Sevitt and Gallagher found, in a series of patients with hip fractures who received no anticoagulants, that almost 30 per cent had venous thrombosis, 18 per cent developed pulmonary embolism, and 10 per cent died of embolism.

It is the purpose of this paper to present two cases of massive pulmonary embolism occurring in patients with fractured neck of the femur during actual operation. Both of these patients had Moore's prostheses inserted at Hamilton General Hospital during 1966, prior to the incident, and both cases ended fatally within half an hour of the embolism.

The difficulty in diagnosing massive pulmonary embolism when the patient is under anaesthesia can well be appreciated, especially as most of these patients are in the age group in which cardiovascular disease is common. The deaths of these patients can, therefore, readily be blamed on the anaesthetic unless autopsy is carried out.

\section{Case 1}

A 59-year-old female was admitted to Hamilton General Hospital with the diagnosis of fractured neck of the right femur. This was confirmed by X-ray. She appeared much older than her stated age, and was mentally confused. She had sustained a stroke two years previously.

On examination, her blood pressure was found to be $210 / 125 \mathrm{~mm}$. $\mathrm{Hg}$, and she had a moderate degree of cardiomegaly. The pulse rate was $86 / \mathrm{min}$. and regular. The electrocardiogram showed sinus rhythm and left ventricular hypertrophy. There was evidence of an old right hemiparesis; the lungs were found to be normal; haemoglobin $10.1 \mathrm{gm}$. per cent.

Under general anaesthesia, a Moore's prosthesis was inserted into the right hip on the day of admission. Recovery was uneventful and the patient was transferred to a chronic ward a few days later, where she received physiotherapy. 
Three months later, movements of the right hip became very limited and painful. X-ray showed lateral and posterior dislocation of the right hip prosethesis. It was decided to attempt closed reduction of the prosthesis under general anaesthesia. Preoperatively, the patient's cardiovascular and respiratory systems appeared stable. Blood pressure was $140 / 90 \mathrm{~mm}$. Hg; Hbg. 10.9 gm. per cent.

\section{Anaesthesia}

4:30 P.M. Premedication: meperidine $25 \mathrm{mg}$, atropine $0.4 \mathrm{mg}$. was administered intramuscularly.

5:40 P.M. Induction: nitrous oxide, oxygen, halothane (1.5 per cent with 50 per cent oxygen ). Maintenance: nitrous oxide, oxygen, halothane ( 0.5 per cent). Spontaneous respiration with the semi-closed absorption circuit.

5:45 P.M. Attempted reduction of prosthesis started.

6:19 P.M. End of attempted reduction of prosthesis. Appeared to be unsuccessful. Patient was breathing 100 per cent oxygen and appeared to be waking up, making slight movements of the head and apparently groaning. Blood pressure was $110 / 70 \mathrm{~mm}$. Hg. Pulse regular.

6:20 P.M. Spontaneous respiration ceased. No radial or carotid pulse palpable. No apex beat heard on auscultation. Cardiac arrest diagnosed.

6:21 P.M. Resuscitative measures started.

6:24 P.M. Heart restarted spontaneously. Blood pressure was 70/? mm. Hg.

6:25 P.M. Spontaneous respiration started. Patient began to move arms and legs.

6:30 p.M. Cardiac arrest again. Cardiac massage restarted. In spite of further resuscitative efforts, heart could not be restarted.

7:00 P.M. Patient pronounced dead.

\section{Post-mortem Report}

"Both pulmonary arteries are plugged with coiled ante-mortem thrombus. The appearance is that of massive terminal pulmonary embolism. The site of this thrombus is probably from the region of the right hip where the tissues adjacent to the false joint contain a large amount of old blood clot and vessels are also thrombosed.

"The heart is moderately enlarged due to dilatation of the right ventricle and hypertrophy of the left ventricle."

\section{CASE 2}

A 68-year-old female was admitted to Hamilton General Hospital with a diagnosis of fractured neck of right femur after a fall. She had been in another hospital with senile dementia, and her activity had been greatly restricted.

X-ray showed a subcapital fracture of the neck of the right femur. The cardiovascular system showed cardiomegaly. Blood pressure was $170 / 110 \mathrm{~mm}$. $\mathrm{Hg}$. There were extrasystoles, but no signs of cardiac failure. The electrocardiogram showed ventricular extrasystoles. No abnormality was found in the lungs.

On the following day, under general anaesthesia, a Moore's prosthesis was inserted into the right hip. This operation was uneventful. 
Six days later, the patient developed right basal pneumonia. With treatment, this cleared over the following two and a half weeks.

One month after insertion of the Moore's prosthesis, X-ray of the right hip showed subluxation of the prosthetic head. It was decided to reduce this under general anaesthesia. Blood pressure was $160 / 90 \mathrm{~mm}$. Hg. There were extrasystoles; no signs of cardiac failure. $\mathrm{Hbg}$. was $10.6 \mathrm{gm}$. per cent. There were a few râles over both lungs on auscultation.

Under general anaesthesia, open reduction of the prosthesis was attempted.

\section{Anaesthesia}

7:00 P.M. Premedication: atropine $0.6 \mathrm{mg}$. was given intramuscularly.

8:00 P.M. Induction: thiopentone (2.5 per cent) $125 \mathrm{mg}$, succinylcholine $60 \mathrm{mg}$, $8.5 \mathrm{~mm}$. oral cuffed endotracheal tube. Controlled respiration.

Maintenance: Nitrous oxide, oxygen, halothane ( $0-0.5$ per cent intermittently).

The prosthetic head could not be reduced into the acetabulum in spite of many attempts at manipulation under direct vision, so the prosthesis was removed and the incision closed.

9:35 P.M. End of operation. Patient's condition satisfactory. Blood pressure $160 / 80 \mathrm{~mm}$. Hg. Patient returned to recovery room.

9:45 P.M. Cyanosis noted, with rapid shallow breathing. This was followed in a short time by disappearance of the radial and carotid pulses. Cardiac arrest diagnosed.

9:46 P.M. Resuscitative measures started.

10:05 P.M. Heart restarted.

10:10 P.M. Spontaneous respiration reappeared. Patient deeply unconscious. Pupils widely dilated and non-reactive to light.

10:50 P.M. Cardiac arrest again. In spite of further attempts at resuscitation, heart could not be restarted.

11:30 P.M. Patient pronounced dead.

\section{Post-mortem Report}

"Large blood clot completely occluding right pulmonary artery and smaller clot partially occluding the left pulmonary artery at its bifurcation into small lobar branches.

"Enlarged heart weighing $630 \mathrm{gm}$. Left ventricular hypertrophy. Narrowing of ostia of coronary vessels, and distension of right ventricle.

"Pelvic thrombophlebitis."

\section{Discussion}

The classical triad described in the aetiology of venous thrombosis by Virchow ${ }^{5}$ is as follows:

1. Slowing of the circulation;

2. Trauma to the vessel wall;

3. Alteration of blood constituents.

In both of the cases described, the patients were lying dormant in bed with 
very little muscular activity, and there is no doubt that circulatory stasis did occur. Another contributory factor in circulatory stasis probably was the fact that they both had some degree of cardiac impairment, though neither appeared to be in cardiac failure at the time of manipulation.

The head of the dislocated prosthesis may have caused compression of many small veins, so that blood dammed up in the veins distal to the point of compression, encouraging stagnation and so thrombosis. The thrombi in these veins were then prevented from moving centrally by the prosthetic head. However, on manipulation, the compression was removed and any thrombi not attached to the vein wall would be free to move centrally and be carried to the lungs. Multiple thrombi, or long thrombi, could then effectively plug up the pulmonary circulation and cause death. Massive pulmonary embolism causing death is usually due to long thrombi coiled up in the pulmonary arterial tree. ${ }^{6}$ This occurred in Case 1 as found at post-mortem. Embolism occurred in both cases during or immediately after manipulation, and this tends to support the hypothesis.

Both of these patients were still under the effects of anaesthesia when cardiac arrest occurred. In the first case, the diagnosis was suspected, though on account of the patient's frail physical condition the possibility of anaesthesia's being a contributory factor could not be ruled out. Post-mortem was required to reveal the correct diagnosis. In Case 2, which occurred approximately two weeks later, the correct diagnosis was made at the time of collapse and was confirmed at post-mortem.

\section{Diagnosis}

Awareness of the possibility of the occurrence is the first essential in diagnosis. In these cases, the massive embolism seemed to be in some way related to the manipulation. The essential feature seems to be that the head of the femur or prosthesis was out of the acetabulum over a period of some days, thus allowing compression of veins and thrombosis to occur.

The difficulty in diagnosis, as has been stated, is accentuated by anaesthesia. Marshall ${ }^{6}$ states, "The diagnosis of the impaction of a pulmonary embolus depends mainly on the signs and symptoms produced by obstruction of the circulation." With the patient under anaesthesia there will be no symptoms, and so we have to depend on (A) clinical signs, (B) electrocardiography, (C) serum enzyme estimation, and (D) pulmonary radiography.

(A) Clinical signs. The clinical effects immediately after impaction of the embolus may be due to the systemic hypotension, to the pulmonary hypertension, and to signs produced at the site of the embolus. Immediate clinical evidence of pulmonary embolism will, therefore, only be present in cases of massive embolism.

(i) Cardiovascular system. In massive embolism, systemic hypotension caused by the low cardiac output will be evident. This occurred in both of these cases. Rapid, weak pulse, pallor, and sweating occur. Cardiac arrhythmias occur frequently.

Pulmonary hypertension occurs due to obstruction in the pulmonary circuit, and this causes right ventricular dilatation and an increase in right ventricular pressure on contraction. The pulmonary second sound is, therefore, accentuated. 
The large right heart may cause increased cardiac dullness to the right of the sternum.

Increased venous pressure is reflected by a higher level of filling of the jugular vein and, perhaps, also by enlargement of the liver. It is probably wise to monitor the central venous pressure of special-risk patients by a catheter placed in the superior vena cava or right atrium. Sudden rise in the central venous pressure will be observed if embolism occurs.

Cyanosis is often seen in pulmonary embolism and is due to stagnation of blood in the vessels or to actual arterial desaturation.

(ii) Respiratory system. Rapid, shallow breathing is observed following massive pulmonary embolism. In some cases, this progresses to apnoea, as occurred in the two cases described.

Bronchospasm has been observed in some cases and was described by Boyer and Curry. ${ }^{7}$ In the two cases described there was no evidence of bronchoconstriction as shown by the ease with which the lungs could be ventilated after the patients collapsed. Gurewich, Thomas, Stein, and Wessler ${ }^{8}$ found evidence of bronchoconstriction in patients they studied. They observed that it may be transient and limited to the early stage of the disease.

(B) Electrocardiography. There is very little agreement about the value of the E.K.G. as a diagnostic method in pulmonary embolism. Multiple changes in the E.K.G. pattern have been reported by many authors., ${ }^{0,10}$ The changes may be summarized as indicating: (a) clockwise rotation of the heart about both a vertical and an antero-posterior axis; $(b)$ signs of right ventricular strain as exemplified by $\mathrm{S}-\mathrm{T}$ shift, $\mathrm{T}$-wave inversions in $\mathrm{V}_{1}, \mathrm{~V}_{2}, \mathrm{~V}_{3}$, and right bundle branch block. These may occur within the first six hours. However, the electrocardiogram is neither a sensitive nor a very specific means for detecting pulmonary embolism. ${ }^{10}$

(c) Serum enzymes. Serum lactic-dehydrogenase (LDH) is raised in cases of pulmonary infarction, while the serum glutamic oxalacetic transaminase is normal. However, the LDH activity is not increased until some hours after the embolism occurs, and so will be of no value in immediate diagnosis unless a previous infarction has occurred. Similarly serum bilirubin increase, associated with pulmonary infarction, is delayed.

(D) Pulmonary radiography. Acute cor pulmonale may become evident by (a) dilated hilar arteries, (b) a dilated pulmonary artery trunk, (c) oligaemia of the lung field, $(d)$ right inflow stasis: dilated azygos vein and superior vena cava, and $(e)$ dilatation of the right ventricle. ${ }^{11}$ Radioisotope scanning-using macroaggregated human serum albumin labelled with either $\mathrm{I}_{131}$ or $\mathrm{Cr}_{51}$-can be safely used in the very ill patient to determine the blood flow to various regions of the lungs. ${ }^{12}$ Pulmonary angiography should be carried out in cases of massive embolism in the acute phase, where embolectomy is being considered. This makes the diagnosis more certain. Simon and Sasahara ${ }^{13}$ state that "a negative examination of good quality performed within 48 hours of the suspect incident makes the diagnosis highly improbable, but after greater delay a negative examination would not exclude pulmonary embolism." This method of diagnosis is tolerated well even by very ill patients. Better results are obtained by catheterizing the main pulmonary artery, but in very ill patients, intravenous injection of the 
contrast medium may be used. Radiography may be carried out in the operating room for patients in extremis. ${ }^{14}$

\section{Acute Physiological Changes in Massive Pulmonary Embolism}

Respiratory system

(a) Physiological dead space. The effect of obstruction of the pulmonary arteries is to cut off the blood supply to a region of the lung while that part of the lung is still capable of being ventilated. This increases the physiological dead space. In massive embolism, this increase may be very marked..$^{15}$

(b) Diffusing capacity. Pulmonary embolism reduces the diffusing capacity only if the area of the capillary bed is reduced. Partial obstruction of one pulmonary artery in man does not reduce the diffusing capacity of the lung until the oxygen uptake of that lung is reduced below 50 per cent of normal. ${ }^{16} \mathrm{Com}$ plete occlusion of one main pulmonary artery causes a marked reduction in diffusing capacity of that lung, while the increase in blood flow through the unoccluded lung does not increase its diffusing capacity. In massive embolism, therefore, there is marked reduction in diffusing capacity.

(c) Venous-arterial shunting. Arterial unsaturation may occur in pulmonary embolism mainly due to shunting of blood from the venous to the arterial system. The shunt may occur through a patent foramen ovale when the right atrial pressure rises, ${ }^{17}$ but in most cases the shunt appears to be in the lung, although the precise anatomical location of the vessels is unknown. ${ }^{6}$

(d) Cyanosis. This is usually manifest in massive pulmonary embolism and is due to $(i)$ stagnation of blood in the vessels as a result of the low cardiac output, or to (ii) arterial desaturation.

(e) Arterial desaturation. This is due mainly to the shunting of blood from the venous to the arterial system, but also to marked reduction in the diffusing capacity of the lungs which occurs in massive embolism. Very low values may be obtained in the acute stage of embolism. ${ }^{18}$

(f) Carbon dioxide differences between end tidal gas and arterial blood. This measurement should, in theory, be an index of the proportion of alveoli which are unperfused, ${ }^{15}$ but high values for the end tidal arterial carbon dioxide tension difference may be obtained, in the absence of embolism, if the patient has chronic lung disease or if respiration is not deep enough. ${ }^{6}$

\section{Cardiovascular system}

Obstruction of one main pulmonary artery in man causes no signs or symptoms. ${ }^{6}$ Paneth ${ }^{19}$ found, while performing embolectomy on patients with massive embolism who were not improving by medical treatment, that in every case one main pulmonary artery was completely blocked, and the other was partially blocked.

The cause of death in massive pulmonary embolism is mechanical obstruction of the pulmonary circulation. This causes a strain on the right ventricle which fails early in patients who have had previous myocardial damage. The low cardiac output also contributes to cerebral and myocardial hypoxia.

Just-Viera and Yeager $^{20}$ found that a fatal outcome from pulmonary embolism by large blood clots could be correlated with a fall in systemic blood pressure to 
less than 50 per cent, a metabolic acidosis, cessation of respiration within 85 seconds of embolization, pupil dilatation within 132 seconds, and a marked depression of the $\mathrm{S}-\mathrm{T}$ interval and inverted $\mathrm{T}$-waves in the electrocardiogram.

Parmley, North, and $\mathrm{Ott}^{21}$ also found that a fall in systemic blood pressure to less than half the initial value usually indicated a fatal outcome. The low cardiac output due to the mechanical blockage causes a low blood pressure. This results in peripheral vasoconstriction, and the systemic resistance increases.

Pulmonary hypertension occurs due to blockage of the pulmonary circulation, and the venous side of the circulation fills with blood. Thus the peripheral veins are collapsed but the central venous pressure is high. ${ }^{19}$

\section{Prophylaxis}

(a) Early ambulation and "stir up" regime after operations and illness are recommended to prevent stagnation of blood and slowing of the circulation. Immobilization in bed leads to venous thrombosis and embolism. ${ }^{22}$

(b) Adoption of a $15^{\circ}$ Trendelenburg position while lying in bed aids greatly in returning venous blood to the heart, and this position may also be of help during operation. Elevation of the limb increases the velocity of blood flow, ${ }^{23,24}$ and McLachlin, McLachlin, Jory, and Rawling have shown this to be more effective than vigorous voluntary contraction of the thigh and calf muscles with the body and lower extremities horizontal. ${ }^{24}$

(c) Anticoagulant therapy. Patients with a fractured neck of femur have a specially high risk of pulmonary embolism. ${ }^{3}$ Sevitt and Gallagher ${ }^{4}$ found that anticoagulant therapy completely prevented pulmonary embolism in their patients, and likewise $\mathrm{Fagan}^{3}$ found in his series that anticoagulants reduced the incidence of embolic phenomena from 34.9 to 5.4 per cent. They recommended that this therapy be started on admission and continued until the patient is active. ${ }^{4}$

\section{TreatMent}

Treatment may be either medical or surgical. Energetic medical treatment is required in the first instance in all cases of massive pulmonary embolism. If the embolism is severe, then medical treatment will not keep the patient alive. Hampson, Milne, and Small ${ }^{25}$ believe that if there is no response to medical treatment within 30 minutes, then recovery without operation is unlikely.

\section{Medical}

(a) Oxygen administration is indicated, since patients with massive pulmonary embolism usually have desaturated arterial blood and a low cardiac output. The arterial oxygen saturation can always be increased by giving 100 per cent oxygen, even though the unsaturation is due partly to a shunt of venous blood. Intermittent positive pressure respiration is indicated if respiration is shallow, irregular, or absent.

(b) Heparin should be injected immediately after a massive embolism. This serves a dual purpose: $(i)$ it prevents further coagulation of blood in the venous 
system, and (ii) it blocks the release of serotonin which may produce bronchospasm. ${ }^{7,8}$

(c) Fibrinolysins. The rationale for the use of these drugs is that in dogs subjected to experimental embolism and killed at increasing intervals, it was found that after five days all traces of thrombosis had disappeared in half of the animals, while the remnants persisting in the remainder were slightly adherent. After two weeks, no traces could be found in any animal examined. ${ }^{26}$ In the group of dogs subjected to massive embolism, shrinkage by lysis was far more striking in those killed after 13 to 16 days; scattered organizing thrombi not over a few centimetres in total length were all that remained of the large volume of emboli reaching the lungs.

In man there is reason to believe that the fibrinolytic system is just as active. Thus, if the heart can compensate and the lytic systems are effective, the patient may survive massive embolism. It is in cases of massive embolism that it is justifiable to use fibrinolytic drugs in an effort to aid the patient's normal mechanism. In patients showing no improvement, embolectomy is indicated. Fletcher, Sherry, Alkjaersig, Smyrniotis, and Jicks ${ }^{27}$ found that the dose of streptokinase required to maintain therapeutic levels without causing fever was $35,000-1,500,000$ units and the activity was maintained by continuous infusion. The amount required each hour was approximately the same as the initial dose.

(d) Digitalis should be given to improve tone in the failing heart. This may be life-saving, especially in those with prior heart disease. In massive embolism, the right ventricle has to work much harder to push blood through the pulmonary circulation, and so needs assistance.

(e) Vasoconstrictors. Most patients with a low blood pressure due to massive embolism already have compensatory peripheral vasoconstriction. Vasoconstrictors may, therefore, have very little effect, though they may be tried, especially when an effort is being made to keep the patient alive for pulmonary embolectomy. Metaraminol may be useful.

(f) Morphine is useful for its sedative effect and should be given intravenously and in small doses.

\section{Surgical Treatment}

(a) Embolectomy. Donaldson, Williams, Scannel, and Shaw ${ }^{28}$ found that 25 per cent of 271 patients whom they studied survived for at least one hour after massive pulmonary embolism. They concluded that one out of every five patients with massive pulmonary embolism lived long enough to allow embolectomy to be carried out. They suggested that the decision to operate should be taken when there is $(i)$ evidence of a failing right ventricle with weak radial pulse, (ii) falling blood pressure, (iii) no response to vasopressors, (iv) irregular respiration, $(v)$ increasing jugular vein pressure, $(v i)$ gallop rhythm present, (vii) accentuation of the pulmonary second sound. However, medical management of patients with massive pulmonary embolism will often be the only therapeutic measure necessary because clinical improvement may occur.

If embolectomy is chosen, certain considerations are important: (i) the diagnosis must be certain, (ii) supportive measures must be continued with 
oxygen and vasopressors, (iii) extracorporeal circulation must be prepared, (iv) after chest closure, the inferior vena cava must be ligated to prevent further embolization from the peripheral venous system. ${ }^{29}$

It has recently been advocated that, in very ill patients, partial cardiopulmonary by-pass should be started at the patient's bedside, in order to allow time to prepare for surgery. ${ }^{30}$ This will ease the load on the right ventricle and improve oxygenation. Such patients have a low fixed cardiac output so that induction of anaesthesia may be very hazardous. The vasodilatation caused by anaesthetic drugs will further reduce coronary blood flow and may lead to cardiac arrest. Metaraminol has been used to prevent this vasodilatation. ${ }^{10}$

(b) Inferior vena caval ligation. Pulmonary embolism is a recurrent event with repeated migration of a blood clot over a period of hours or days. If, therefore, repeated emboli are passing to the lungs, the inferior vena cava should be ligated to prevent massive fatal embolism.

(c) Venous thrombectomy is indicated where there is obvious venous thrombosis. This may be displayed by venography.

\section{SUMMARY}

Two cases of massive pulmonary embolism during anaesthesia are presented. Rapid evolution of events did not allow definitive surgical treatment. The literature is reviewed and suggestions for prophylaxis and treatment are presented.

\section{RÉSUMÉ}

A l'Hôpital Général de Hamilton, on a observé 40 cas d'embolie pulmonaire sur 14,568 admissions, au cours de l'année 1966. De ce nombre, 21 ont été mortelles ( 13 cas de médecine et 8 cas de chirurgie).

Nous vous présentons deux cas de fracture du col du fémur qui ont éu une prothèse de Moore. Dans les deux cas, les prothèses se sont par la suite luxées, et pendant qu'on tentait de les réduire sous anesthésie générale, les deux ont fait une embolie pulmonaire mortelle.

Nous faisons ressortir la difficulté de diagnostic d'embolie pulmonaire massive; on peut tout de même arriver à faire ce diagnostic par les moyens suivants:

(1) Il faut être conscient du fait que l'embolie peut se produire dans ce genre de cas.

(2) Retenir les signes cliniques-hypotension, cyanose, changements dans l'E.C.G., élévation de la pression veineuse centrale. De plus, la respiration peut être rapide et superficielle et un bronchospasme peut se produire.

(3) L'évaluation des enzymes du sérum peut aider si le malade a déjà fait un infarctus pulmonaire. L'activité de L.D.H. peut être augmentée, les transaminases sont normales et la bilirubine du sérum augmentée.

(4) La radiographie pulmonaire peut aussi être utile (a) écran, (b) exploration radio-isotope, $(c)$ angiographie pulmonaire.

Certains changements physiologiques aigus se produisent dans l'embolie pulmonaire massive. Ce sont: (a) augmentation de l'espace mort physiologique, 
(b) diminution du pouvoir de diffusion des poumons, (c) dérivation veineuseartérielle dans les poumons, $(d)$ cyanose, $(e)$ désaturation artérielle, $(f)$ différence d'acide carbonique entre le gaz d'apport et le sang artériel, $(g)$ diminution du débit cardiaque et baisse de la pression sanguine, $(h)$ affaissement subit des veines périphériques, mais haute pression veineuse centrale.

La prévention comprend $(a)$ un éveil constant pour prévenir tout ralentissement de la circulation, $(b)$ l'installation du malade alité en position de Trendelenburg à 15 degrés pour faciliter le retour veineux, $(c)$ l'usage d'anti-coagulants pour les cas de fracture du col du fémur.

Le traitement de l'embolie massive est (1) médical et (2) chirurgical.

1. Le traitement médical comprend l'oxygénation, avec ou sans respiration assistée ou contrôlée, l'héparinisation, l'usage de fibrolysines, la digitale pour améliorer le tonus cardiaque, les vasoconstricteurs, et la morphine comme sédatif.

2. Au point de vue chirurgical, l'embolectomie est indiquée si le traitement médical ne produit pas d'amélioration. La dérivation cardio-pulmonaire est essentielle si l'on veut opérer dans des conditions satisfaisantes. Il faut veiller à bien choisir l'anesthésique à cause du faible débit cardiaque. Il faut ligaturer la veine cave inférieure après l'embolectomie pour prévenir une nouvelle embolie.

La thrombectomie veineuse est indiquée dans les rares cas de thrombose veineuse évidente.

\section{REFERENCES}

1. Hèlıe, M. Inflammation de l'artère pulmonaire: Mort subite. Bull. Soc. anat. Paris. 8: 254 (1837).

2. Matas, R. The Present Status of the Postoperative Pneumonopathies: A Cursory Review of the Question. Internat. Clin. 2: 1 (1931).

3. FAGAN, D. G. Prevention of Venous Thromboembolic Phenomena Following Operations on the Neck of the Femur. Lancet. 1: 846 (1964).

4. Sevitt, S. \& Gallagher, M. G. Prevention of Venous Thrombosis and Pulmonary Embolism in Injured Patients. Lancet. 2: 981 (1959).

5. VIRchow, R. Die Pfropfbildungen und Verstopfungen in den Gefassen. Handb. Spec. Path. u. Therap., Band 1. Erlangen (1854).

6. Marshall, R. Pulmonary Embolism: Mechanism and Management. Springfield, Illinois: Charles C. Thomas (1965).

7. Boyer, N. H. \& CurRY, J. J. Bronchospasms Associated with Pulmonary Embolism. Arch. Internat. Med. 73: 403 (1944).

8. Gurewich, V.; Thomas, D. P.; Stein, M; \& Wesslen, S. Bronchoconstriction in the Presence of Pulmonary Embolism. Circulation. 28: 339 (1963).

9. PhIllips, E. \& Levine, H. D. A Critical Evaluation of Extremity and Precordial Electrocardiography in Acute Cor Pulmonale. Am. Heart J. 39: 205 (1950).

10. Litrmans, D. Observation on the Electrocardiographic Changes in Pulmonary Embolism. From: Pulmonary Embolic Disease, ed. A. A. Sasahara and M. Stein. Philadelphia: Grune and Stratton (1965).

11. Fletschner, F. G. Pulmonary Embolism. Clin. Radiol. 13: 169 (1962).

12. WAGner, H, N. Radioisotope Scanning in Pulmonary Embolic Disease. From: Pulmonary Embolic Disease, ed. A. A. Sasahara and M. Stein, Philadelphia: Grune and Stratton (1965).

13. Simon, M. \& Sasahara, A. A. Observations on the Angiographic Changes in Pulmonary Thromboembolism. From: Pulmonary Embolic Disease, ed. A. A. Sasahara and M. Stein. Philadelphia: Grune and Stratton (1965).

14. Sautren, R. D. The Technique of Pulmonary Embolectomy with the Use of Cardiopulmonary Bypass. J. Thoracic \& Cardiovasc. Surg. 53: 268 (1967).

15. Severinghaus, J. W. \& Stupfec, M. Alveolar Dead Space as an Index of Distribution of Blood Flow in Pulmonary Capillaries. J. Appl. Physiol. 10: 335 (1957). 
16. Turino, G. M.; Brandfonbrewer, M.; \& Fishman, A. P. The Effect of Changes in Ventilation and Pulmonary Blood Flow on the Diffusing Capacity of the Lung. J, Clin. Invest. 38: 1186 (1959).

17. Elliott, G. B. \& Beamish, R. E. Embolic Occlusion of Patent Foramen Ovale. Circulation. 8: 394 (1953).

18. Robin, E. D.; Forkner, C. E.; Bronberg, P. A.; Croteau, J. R.; \& Travis, D. M. Alveolar Gas Exchange in Clinical Pulmonary Embolism. New England J. Med. 262: 283 (1960).

19. Paneth, M. Pulmonary Embolectomy: An Analysis of 12 Cases. J .Thoracic \& Cardiovase. Surg. 53: 77 (1967).

20. Just-Viera, J. D. \& Yeacer, G. H. Massive Pulmonary Embolism: Immediate and Late Physiologic Changes. Circulation. 28: 745 (1963).

21. Parmley, L. F.; North, R. L.; \& OTt, B. S. Haemodynamic Alterations of Acute Pulmonary Thromboembolism. Circulation. 24: 1011 (1961).

22. Sevitt, S. \& Gallagher, N. Venous Thrombosis and Pulmonary Embolism. Brit. J. Surg. 48: 475 ( 1961$)$.

23. Kvale, W. F.; Smith, L. A.; \& Allen, E. V. Speed of Blood Flow in the Arteries and in the Veins of Man. Arch. Surg. 40: 344 (1940).

24. Mclachlin, A. D.; McLachuin, J. A.; Jory, T. A.; \& Rawling, E. G. Venous Stasis in the Lower Extremities. Am. Surg. 152: 678 (1960).

25. Hampson, J.; Milne, A. C.; \& Small, W. P. The Surgical Treatment of Pulmonary Embolism. Lancet. 2: 402 (1961).

26. Wessler, S.; Reimer, L.; Freiman, D. G.; Reimer, S. M.; \& Lertzman, M. Seruminduced Thrombus: Studies of Its Induction and Evolution under Controlled Conditions in Vivo, Circulation. 20:864 (1959).

27. Fletcher, A. P.; Sherry, S.; Alkjaersig, N.; Smyrniotis, F. E.; \& Jick, S. The Maintenance of a Sustained Thrombolytic State in Man: II. Clinical Observations on Patients with Myocardial Infarction and Other Thromboembolic Disorders. J. Clin. Invest. 38: 1111 ( 1959 ).

28. Donaldson, G. A.; Williams, C.; Scanneld, J. G.; \& Shaw, R. A Re-appraisal of the Application of the Trendelenberg Operation to Massive Fatal Embolism. New England J. Med. 268: 171 (1963).

29. Rosenberg, D. M. L.; Pearce, C.; \& McNulty, J. Surgical Treatment of Pulmonary Embolism. J. Thoracic \& Cardiovasc. Surg. 47: 1 (1964).

30. Cooley, D. A. \& Beall, A. C., Jr. Surgical Treatment of Acute Massive Pulmonary Embolism Using Temporary Cardiopulmonary Bypass. Dis. Chest. 41: 102 (1962). 